\title{
MODIFICATION OF GENE SUPPRESSION IN DROSOPHILA MELANOGASTER BY SEX CHROMOSOMES I. EFFECT OF THE Y CHROMOSOME ON VARIEGATION IN MALPIGHIAN TUBULES OF $w^{m 4}$ LARVAE
}

INGEBORG HARTMANN-GOLDSTEIN and GREGOR KOLIANTZ*

Genetics Department, Sheffield University, Sheffield S10 2TN, U.K.

Received 5.vi.81

\section{SUMMARY}

\begin{abstract}
The effect of the $Y$ chromosome on white variegation associated with $\operatorname{In}(1) w^{m 4}$ has been investigated by comparing the occurrence, proportion and distribution of colourless cells in the Malpighian tubules of $X O, X Y$ and $X Y Y$ larvae cultured at $25^{\circ} \mathrm{C}$ or $15^{\circ} \mathrm{C}$. The results confirmed previous observations that the $Y$ chromosome suppresses variegation, and showed that its loss from the $X Y$ complement has a much greater effect on the proportion of colourless cells than its addition. The variegation is markedly more affected by $Y$-chromosome constitution than by culture temperature. Colourless cells are non-randomly distributed within and between tubules; neither chromosome constitution nor temperature appears to modify these distribution patterns.
\end{abstract}

\section{INTRODUCTION}

IN Drosophila, genes transposed by chromosomal rearrangement to the vicinity of heterochromatin are frequently expressed in only a proportion of cells, so that the affected tissue is variegated (for review see Spofford, 1976). Addition of $Y$ chromosomes usually depresses the variegation and conversely, their deletion enhances the heterochromatic position effect. Occasionally the $Y$ chromosome constitution has far-reaching consequences; for example flies carrying certain rearrangements will only survive if they also carry an additional $Y$ chromosome and on the other hand rearrangements which apparently do not affect the phenotype of normal males will induce variegation in $X O$ individuals.

The mechanisms underlying variegated position effect and its modification are not yet known but a major step forward has been made by the observation that in $D$. melanogaster the effect is decreased by a deficiency of histone genes, deletion of a portion of the histone gene cluster being less effective than deletion of the whole cluster (Khesin and Leibovitch, 1978; Moore et al., 1979). In flies with additional $Y$ chromosome material a presumably compensatory increase in the number of histone genes occurs (Chernyshev et al., 1980). We are attempting to quantify the relationships between sex chromosome constitution and variegation in larval and adult tissues of $D$. melanogaster at different levels of

\footnotetext{
* Present address: Department of Biology, The University for Teacher Education, 49 Roosevelt Avenue, Tehran-15, Iran.
} 
organisation. White-variegation in Malpighian tubules provides a favourable larval system, because the affected cells can be accurately identified and the structure of these organs is suited to a quantitative approach. Following a preliminary communication (Koliantz and HartmannGoldstein, 1976), we report here on variegation in the Malpighian tubules of male $w^{m 4}$ larvae with two, one or no $Y$ chromosomes.

\section{Materials AND MEthods}

For descriptions of strains and mutants, see Lindsley and Grell (1968). The homo/hemizygous-viable strain $\operatorname{In}(1) w^{m 4}$ kindly provided by the University of Umeå was used to investigate white-variegated males with the normal sex chromosome constitution. We obtained $w^{m 4} / O$ flies by crossing $w^{m 4} / Y$ males with females of the attached- $X$ strain $O / \mathrm{C}(1) \mathrm{RM} y^{2} s u\left(w^{a}\right) w^{a} / X Y L . Y S v f B$, held in our laboratory. Marked $Y$ chromosomes have been regarded as abnormal because they have a long history of irradiation (Brosseau et al., 1961) and we avoided the use of such chromosomes. To obtain $w^{m 4}$ males with an additional $Y$ chromosome, $w^{m 4} / Y$ males were crossed with $\operatorname{In}(1) w^{m 4}-N^{264-84 R}$, y $s n / \mathrm{FM}_{3}$, $y^{31 d} s c^{8} d m B 1 / Y$ (hereafter referred to as $w^{m 4}-N / \mathrm{FM}_{3} / Y$ ) females, synthesised by Mislove (1954) and provided by the University of Umeå. Female progeny showing the $N$ but not the $B$ phenotype were selected. The $w^{m 4}-N / w^{m 4}$ and $w^{m 4}-N / w^{m 4} / Y$ genotypes were morphologically distinguishable because of reduced variegation in the eyes of the females with the additional $Y$ chromosome (this was confirmed by ovarian karyotype analysis). The $w^{m 4}-N / w^{m 4} / Y$ females were crossed with $w$ males, the karyotype of each female being subsequently checked. From the male progeny, larvae with predominantly wild-type Malpighian tubules were selected and the ganglial metaphase configurations analysed; those larvae with an additional $Y$ chromosome were used for study.

Flies were reared on yeast-glucose medium. Low culture temperature enhances $w^{m 4}$ variegation, and to widen the scope of these studies, observations were made on sibling cultures grown at 25 and $15^{\circ} \mathrm{C}$ respectively. Malpighian tubules from third instar larvae were fixed in 1 per cent aqueous $\mathrm{OsO}_{4}$ for $10 \mathrm{~min}$ at room temperature, hydrolysed in $1 \mathrm{~N} \mathrm{HCl}$ for $5 \mathrm{~min}$ at $60^{\circ} \mathrm{C}$ and stained in 1 per cent orcein in 70 per cent acetic acid.

\section{Results}

The Malpighian tubules in Drosophila (for review see Wessing and Eichelberg, 1978) consist of an anterior and a posterior pair of slender strands with blind distal ends, the members of each pair fusing to form a common ureter which opens into the gut. Surrounding the lumen of each strand are epithelial cells of two clearly distinguishable types: type I cells are pigmented in $w^{+}$individuals (except in the initial segments of the anterior strands) and predominate, while the less numerous and generally isolated type II cells are small, flattened and unpigmented. In whitevariegated strains some type I cells are colourless and can readily be distinguished from the surrounding pigmented cells after suitable fixation and staining (Hartmann-Goldstein et al., 1976), as shown in fig. 1. The 


\section{Plate I}

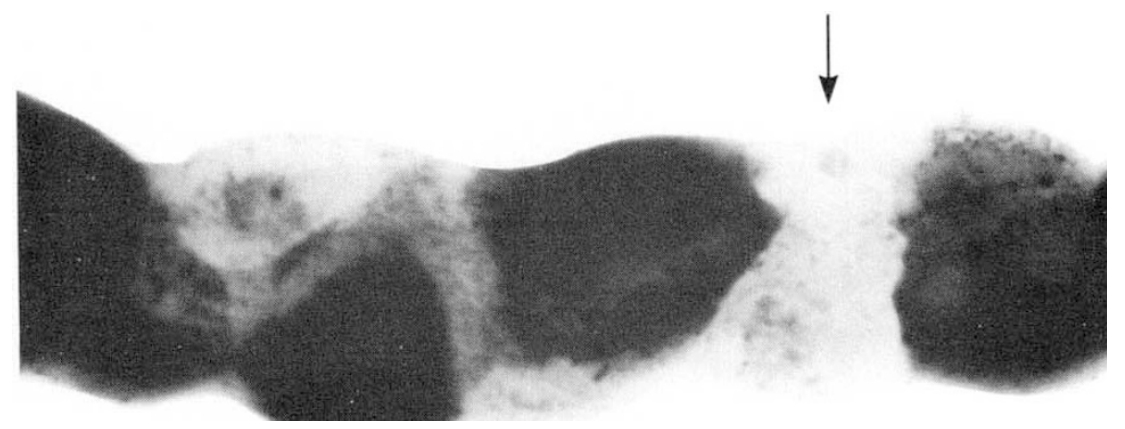

FIG. 1.-Part of an $\mathrm{OsO}_{4}$-fixed, orcein-stained Malpighian tubule from a $w^{m 4} / \mathrm{O}$ third instar larva, showing three unpigmented type I cells and one type II cell (arrow), $\times 540$. 
colourless cells referred to below are unpigmented type I cells in a pigmented region of the strand. The $X$ chromosome quoted in the text and tables carried the $w^{m 4}$ inversion.

\section{(i) Occurrence of variegation}

To determine the effect of $Y$ chromosome constitution on the proportion of variegated individuals, 160 larvae of each chromosome constitution (80 each reared at 25 and $15^{\circ} \mathrm{C}$ ) were examined. Colourless cells were present in every $X O$ larva; of the $X Y$ and $X Y Y$ larvae reared at $25^{\circ} \mathrm{C}$, 49 and 26 respectively contained colourless cells and the corresponding numbers for $15^{\circ}$-reared larvae were 56 and 31 . At both temperatures the differences between the three chromosomal groups were statistically highly significant. All $X O$ larvae had colourless cells in each of the four strands whereas in the $X Y$ and $X Y Y$ larvae one or more strands were usually unaffected. Since the mean number of affected strands per larva did not differ significantly at 15 and $25^{\circ} \mathrm{C}$ in any of the chromosomal groups, the temperature data were pooled, giving highly significantly different values of 4 for $X O, 1 \cdot 2375$ for $X Y$ and 0.5125 for $X Y Y$ animals.

The relative susceptibility of different strands to position effect was investigated by noting the proportions of $X Y$ and $X Y Y$ larvae with 0-4 variegated strands. Pooling the data from equal numbers of larvae reared at 25 and $15^{\circ} \mathrm{C}$, in $X Y Y$ animals the observed values corresponded quite well with a predicted random distribution (table 1), but in the $X Y$ group the observed distribution was, overall, clearly non-random. More $X Y$ larvae than expected either were not variegated at all or had 3 or 4 affected

TABLE 1

Comparison between observed $(O)$ and expected $\left(E^{*}\right)$ numbers of variegated larvae classified according to distribution of colourless cells among the four Malpighian strands, assuming random distribution between strands (pooled $25^{\circ} \mathrm{C}$ and $15^{\circ} \mathrm{C}$ data)

Sex chromosome constitution

$$
\begin{array}{lllll} 
& \multicolumn{1}{c}{X Y} & \multicolumn{2}{c}{X Y Y} \\
\text { O } & \text { E } \quad \frac{(|\mathrm{O}-\mathrm{E}|-0.5)^{2}}{\mathrm{E}} & \mathrm{O} & \mathrm{E} & \frac{(|\mathrm{O}-\mathrm{E}|-0.5)^{2}}{\mathrm{E}}
\end{array}
$$

Strands variegated:

All
2 ant., 1 post.
1 ant., 2 post.
2 ant.
2 post.
1 ant., 1 post.
1 ant.
1 post.
None
Total
$\chi^{2}$
df
$P$

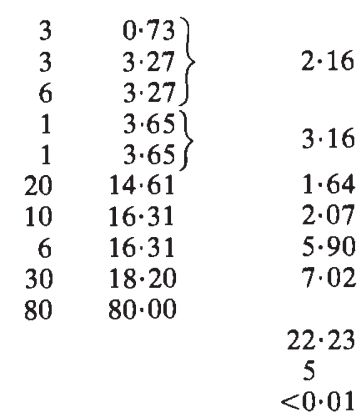

$\begin{array}{rl}\left.\begin{array}{r}0.02 \\ 0.29 \\ 0.29 \\ 1.00 \\ 1.00\end{array}\right\} & \\ 3.99 & 3.22 \\ 13 \cdot 59 & \\ 13.59 & 0.06 \\ 46.23 & 0.09 \\ 80.00 & 3.69 \\ & 0.39 \\ & 7.46 \\ & 4 \\ & \text { n.s. }\end{array}$

* Based on observed mean number of variegated strands: 1.2375 in $X Y, 0 \cdot 5125$ in $X Y Y$. Where expected numbers were very low, $\chi^{2}$ was calculated using pooled values (bracketed in table). 
strands, and fewer than expected had colourless cells in only 1 strand. Such a distribution would for example be accounted for if some sort of threshold has to be reached before variegation occurs. The data on both $X Y$ and $X Y Y$ larvae with only a single affected strand suggest that anterior strands may be somewhat more susceptible than posterior strands to variegation (this has recently been confirmed by independent experiments, to be published elsewhere). In $X Y$ animals with 2 variegated strands, although the total observed and expected numbers corresponded well, larvae with one anterior and one posterior affected strand were more frequent than expected and the number in which both affected strands belonged to the same pair was correspondingly low. One might envisage that variegation in one strand interferes with variegation in the other strand of the same pair.

\section{(ii) Proportion of colourless cells in variegated larvae}

Epithelial cells are generally larger and less intensely pigmented in anterior than in posterior strands, and the strands themselves are more easily detached from the fat body. Pigmented and unpigmented cells were therefore counted only in the anterior pair. At both temperatures marked differences between the three chromosomal groups were found, variegation again being highest in $X O$ and lowest in $X Y Y$ larvae. These differences were statistically highly significant even when only variegated larvae were taken into account (table 2). The proportions of colourless cells (unlike the proportions of variegated larvae dealt with in the previous section) did not reach 100 per cent in the $X O$ groups, and are therefore a better measure of the relative effect of loss or gain of a $Y$ chromosome on males with the normal sex chromosome constitution. At both temperatures the difference between $X O$ and $X Y$ larvae was greater than between $X Y$ and $X Y Y$; this was particularly marked at $25^{\circ} \mathrm{C}$, where the proportion of colourless cells in the $X O$ group was almost 40 times greater than in $X Y$ whereas in $X Y$ it was only about 8 times that in $X Y Y$. At least for this variable, loss of a chromosome is not merely the converse of gain.

All the results reported above are consistent with the frequently observed phenomenon that low culture temperature enhances variegation. However, the magnitude of the temperature effect differs noticeably between the various criteria we have used to measure variegation. Only for proportions of colourless cells within larvae were the differences statistically significant and even here a temperature difference of $10^{\circ} \mathrm{C}$ was noticeably less effective than the addition or deletion of one $Y$ chromosome. These conclusions were confirmed by a two-way analysis of variance, which also showed a significant interaction between the effects of temperature and chromosome constitution: temperature has a relatively greater effect on variegation in $X Y$ than in either $X O$ or $X Y Y$ larvae.

\section{(iii) Spatial distribution of colourless cells within strands}

In $X Y$ and $X Y Y$ larvae the colourless cells always occurred singly i.e., each colourless cell was in contact with pigmented cells only. In $X O$ larvae however, 21 per cent of colourless cells were clustered in groups of 2-5 cells when the larvae were reared at $25^{\circ} \mathrm{C}$; at $15^{\circ} \mathrm{C}$ the proportion of clustered cells rose to 26 per cent and three groups of 6 cells were observed. 


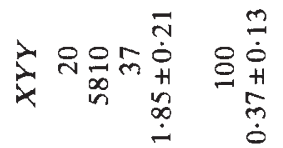

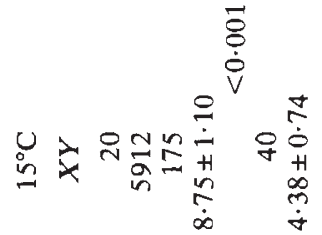

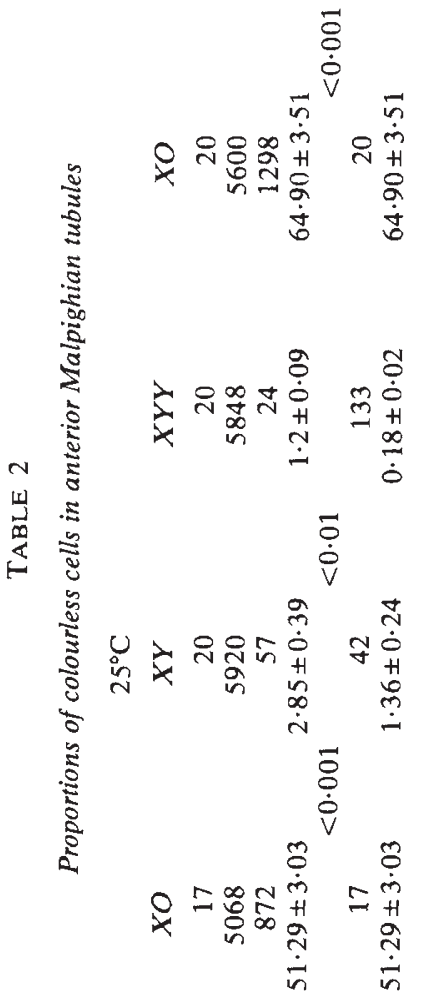

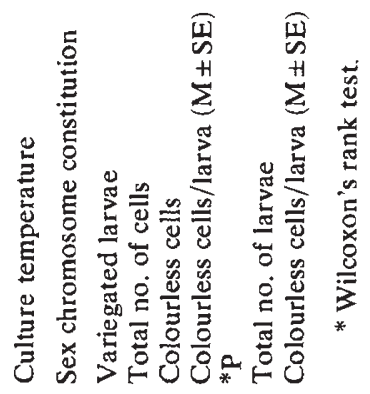


Assuming a random distribution, if each cell is on average in contact with $n$ other cells the expected number of colourless cells in contact only with pigmented celis is $C s(1-p)^{n}$, where $C s$ is the observed number of colourless cells and $p$ is the proportion of colourless cells in the population. Analysis of the results presented in table 3 showed that in $X O$ larvae of both

TABLE 3

Numbers of singly-occurring colourless cells in Malpighian tubules

Culture temperature

Sex chromosome constitution

Total no. of cells

Total no. of colouriess cells

Single colourless cells observed

\begin{tabular}{rrrrrr} 
& $25^{\circ} \mathrm{C}$ & & \multicolumn{3}{c}{$15^{\circ} \mathrm{C}$} \\
$X O$ & $X Y$ & $X Y Y$ & $X O$ & $X Y$ & $X Y Y$ \\
5068 & 5920 & 5848 & 5600 & 5912 & 5810 \\
872 & 57 & 24 & 1298 & 175 & 37 \\
693 & 57 & 24 & 979 & 175 & 37
\end{tabular}

temperature groups and in $X Y$ larvae reared at $15^{\circ} \mathrm{C}$ the observed distribution was hyperdispersed, and that the arrangement of cells in the tubule i.e., whether a cell is assumed to be in contact with 2,3 or 4 others, does not affect this conclusion. In the remaining experimental groups the numbers of unpigmented cells were too low for hyperdispersion to be detectable and the absence of clusters was therefore not statistically significant. Very similar results were obtained when the same data were analysed using a runs test which assumes a strictly linear arrangement of tubule cells; the assumption that each cell is in contact with just 2 others allows one to predict the proportion of colourless cells occurring in groups of different sizes (table 4). The analysis confirmed the presence, in $X O$, of single colourless cells in larger numbers than expected; it also showed that fewer than expected occurred in pairs and indicated that somewhat more than expected occurred in groups of 5 or 6 cells.

Colourless cells seemed to be more common towards the distal than the proximal ends of the tubules. To test this, we compared the numbers of colourless cells in the distal, middle and proximal thirds of both anterior strands from $8 X O$ and $8 X Y$ larvae, respectively 4 from each temperature group. There were no significant differences between $25^{\circ} \mathrm{C}$ - and $15^{\circ} \mathrm{C}$ reared animals and the data from these groups were pooled. Of 300 colourless cells in $X O$ larvae, 95, 81 and 124 respectively were found in the proximal, middle and distal thirds of the tubules; the numbers in the middle third were significantly lower, and those in the distal third significantly higher than expected on a random basis. In the $X Y$ group only 52 colourless cells were found in the 8 larvae examined, and the regional differences were not statistically significant, probably because of the small numbers involved (see Discussion).

\section{Discussion}

The decrease in variegation in the Malpighian tubules of male $w^{m 4}$ larvae which accompanied the increase in number of $Y$ chromosomes reflects the "typical" response (Spofford, 1976) of variegated phenotypes to the $Y$ chromosome. Few workers have however studied this response 
TABLE 4

Comparison between observed $(O)$ and expected $\left(E^{*}\right)$ numbers of groups of colourless cells in $X O$ larvae, assuming linear arrangement of Malpighian tubule cells

Culture temperature

No. of cells

in group:

$\begin{array}{crcr}1 & 693 & 597.7 & 15.04 \\ 2 & 62 & 102.9 & 15.83 \\ 3 & 11 & 17.7 & 2.17 \\ 4 & 3 & 3.04 & \\ 5 & 2 & 0.52 \\ 6 & 0 & 0.09 & 0.20 \\ \text { Totalst } & 771 & 721.95 & \\ \chi^{2} & & & 33.24 \\ \text { df } & & & 3 \\ \text { P } & & & <0.001\end{array}$

$25^{\circ} \mathrm{C}$

$O \quad E \quad \frac{(|O-E|-0.5)^{2}}{E}$

O $15^{\circ} \mathrm{C}$

$\mathrm{E} \quad \frac{(|\mathrm{O}-\mathrm{E}|-0.5)^{2}}{\mathrm{E}}$

* Assuming that the distribution of colourless cells is random, the expected relative frequency of a group of $n$ colourless cells equals the probability that the cell at one end of the group is preceded by a pigmented cell and followed by $(n-1)$ colourless cells and a pigmented cell: this probability is $p^{n-1}(1-p)^{2}$ where $p$ is the proportion of colourless cells in the population. The expected number of such groups is the product of this expression and the total number of colourless cells.

$\dagger$ Calculations are based on cell number; total numbers of observed and expected groups therefore do not necessarily correspond.

quantitatively, and no statistical information has been available on whitevariegation in the Malpighian tubules of $D$. melanogaster. In $w^{m 2}$ larvae of $D$. hydei with presumed $X X Y$ and $X X Y Y$ constitutions, Gloor et al. (1967) observed that two additional chromosomes had more than twice the effect of one on the proportion of colourless cells. Their results do not conflict with our observation that the difference between $X O$ and $X Y$ larvae is far greater than that between animals with $X Y$ and $X Y Y$ constitutions because, apart from possible species differences and differences in experimental design, Gloor and his colleagues in effect added either one or two $Y$ chromosomes to the normal sex chromosome complement whereas we either added a $Y$ chromosome or took one away. The deletion of a chromosome would on general grounds be expected to have more effect than addition; this view is supported by the observation (Bahn, 1971) that variegation for an isoamylase differs more between $X O$ and $X Y$ than between $X Y$ and $X Y Y$ adults of $D$. melanogaster.

The pattern of colourless cells in $D$. hydei Malpighian tubules is random (Beck et al., 1979) or nearly random (Gloor et al., 1967; van Breugel, 1973), with a slight tendency for cells of like pigmentation to form clusters. van Breugel concluded that in Malpighian tubules determination of pigment formation usually occurs just after the last cell division, but may occur somewhat earlier and give rise to clones of colourless cells. The few groups of colourless cells we observed in $X O$ larvae presumably correspond to clones, but on the whole significantly fewer clusters were found than would be expected in a random distribution. It seems that in 
D. melanogaster some additional influence on the pattern of colourless cells, for example active migration of cells after the final mitotic division, is involved. One cannot exclude the possibility that such mechanisms operate also in other species, where however their effects may be masked by a greater tendency for cloning to occur than is the case in D. melanogaster.

Our observations suggest that the lowest proportion of colourless cells occurs towards the middle of the anterior strands, and support the finding of van Breugel (1973) that there are somewhat more in proximal than in distal regions. In all three of these pigmented regions the nuclei fall into three discrete DNA classes (Hartmann-Goldstein, unpublished). Those with the lowest DNA content belong to type II cells, which are always unpigmented. The two remaining classes are found in type I cells, nuclei in the higher class being the more numerous in proximal regions whereas those in the lower class predominate near the distal end. Thus, the spatial distribution of nuclei of different DNA content is reminiscent of the distribution of colourless type I cells in variegated animals, and to investigate the possibility that absence of pigment in type I cells is related to the degree of polyteny, we compared the Feulgen-DNA contents of pigmented and unpigmented cells. Nuclei of the two higher DNA classes were present in similar proportions in pigmented and in unpigmented cells, suggesting that DNA content and position effect are not connected.

As noted under (i) in the results section, the relative frequencies with which variegation occurs in different strands and combinations of strands in $X Y$ and $X Y Y$ larvae are consistent with the hypothesis that some threshold must be crossed for variegation to occur in a given animal. This hypothesis is supported by the relative frequencies of affected cells found in these larvae. Calculations showed that in the $X Y$ and $X Y Y$ groups the statistical distributions of numbers of colourless cells were positively skewed, and in the $X Y Y$ group the distribution was also positively kurtotic, i.e., in both $X Y$ and $X Y Y$ animals the colourless cells were non-normally distributed. It must be remembered that both these groups contain very few colourless cells, and some errors in determining the precise number of such cells in a given animal cannot be excluded. However, the difference in size between type II and unpigmented type I cells is marked (fig. 1), so that errors are unlikely to be frequent and should not significantly affect the results. In view of the small numbers of colourless cells in $X Y$ and $X Y Y$ larvae the statistical distributions might be expected to be of the Poisson rather than the normal type. The observations in fact fitted a Poisson distribution well, provided only variegated larvae were taken into consideration. For example, in $X Y Y$ larvae reared at $15^{\circ} \mathrm{C}, 20$ variegated larvae were observed to have varying numbers of colourless cells corresponding to a Poisson distribution in which approximately 4 non-variegated larvae would be expected. In this sample 80 non-variegated larvae were actually found, suggesting that the majority of the non-variegated larvae formed a population distinct from the variegated animals. Similar results were obtained with $X Y Y$ larvae reared at $25^{\circ} \mathrm{C}$ and with $X Y$ larvae reared at either 25 or $15^{\circ} \mathrm{C}$. In $X O$ larvae the position effect was so powerful that all animals were affected and many more colourless cells were present in each; here the statistical distribution of numbers of colourless cells per larva was approximately normal. 
In our attempts to assess the effect of the $Y$ chromosome on the spatial distribution of colourless cells a consistent difficulty arose from the fact that the groups of larvae had widely different proportions of colourless cells. In $X O$ larvae, and in $X Y$ larvae reared at $15^{\circ} \mathrm{C}$, the distribution of colourless cells within Malpighian strands was significantly hyperdispersed, but too few colourless cells were present in the other experimental groups for a non-random distribution of this type to be detectable. Conversely, a significantly non-random distribution of variegated strands within and between animals was found in experimental groups with relatively few colourless cells but not in the $X O$ groups, in which colourless cells were present in every strand in every animal. There is no evidence suggesting that $Y$ chromosome constitution fundamentally alters the pattern of occurrence of colourless cells in Malpighian tubules. We conclude that the marked effect of the $Y$ chromosome on the proportion of such cells will, in a given case, either reveal or conceal the inherently non-random distribution.

Acknowledgements. - We express our gratitude to D. J. Goldstein for generous advice and help with statistical procedures throughout the work.

\section{REFERENCES}

BAHN, E. 1971. Position-effect variegation for an isoamylase in Drosophila melanogaster. Hereditas, 67, 79-82.

BECK, H., VAN BREUGEL, F. M. A., AND SRDIĆ, Z. 1979. A marked ring- $Y$-chromosome in Drosophila hydei with a new type of white variegation. Chromosoma (Berlin), 71, 1-14.

BREUGEL, F. M. A. VAN 1973. Cell clustering and pleiotropy in white-variegated eyes and Malpighian tubes of Drosophila hydei. Genetics, 75, 323-334.

Brosseau, G. E., NiCOLetTi, B., GRell, E. H., AND LindSLEY, D. L. 1961. Production of altered $Y$ chromosomes bearing specific sections of the $X$ chromosome in Drosophila. Genetics, 46, 339-346.

CHERNYSHEV, A. I., BASHKIROV, B. A., LEIBOVITCH, B. A., AND KHESIN, R. B. 1980. Increase in the number of histone genes in case of their deficiency in Drosophila melanogaster. Molec. gen. Genet., 178, 663-668.

GLOOR, H., VAN BREUGEL, F. M. A., AND VOLKERS, W. S. 1967. Some observations on variegation in Drosophila. Genetica, 38, 95-114.

HARTMANN-GOLDSTEIN, I., KOLIANTZ, G., AND HOYLAND, M. 1976. Methods for studying the distribution of pigment in Malpighian tubules of Drosophila melanogaster. Stain Technol., 51, 119-123.

KHESIN, R. B., AND LEIBOVITCH, B. A. 1978. Influence of deficiency of the histone genecontaining 38B-40 region on $X$-chromosome template activity and the white gene position effect variegation in Drosophila melanogaster. Molec. gen. Genet., 162, 323-328.

KOLIANTZ, G., AND HARTMANN-GOLDSTEIN, I. 1976. Quantitative studies on suppression of variegation in Malpighian tubules by sex chromosomes. Fifth European Drosophila Research Conference, Louvain-La-Neuve (Abstract).

LINDSLEY, D. L., AND GRELL, E. H. 1968. Genetic variations of Drosophila melanogaster. Car. Inst. Wash. Publ. No. 627.

MISLOVE, R. F. 1954. A constant source of $X X Y$ (free-X) females. Dros. Inf. Serv., 28, 137.

MOORE, G. D., PROCUNIER, J. D., CROSS, D. P., AND GRIGLIATTI, T. A. 1979. Histone gene deficiencies and position-effect variegation in Drosophila. Nature, 282, 312-314.

SPOFFORD, J. B. 1976. Position-effect variegation in Drosophila. In The Genetics and Biology of Drosophila, eds. M. Ashburner and E. Novitski, Vol. 1c, pp. 955-1018. Academic Press, London.

WESSING, A., AND EICHELBERG, D. 1978. Malpighian tubules, rectal papillae and excretion. In The Genetics and Biology of Drosophila, eds. M. Ashburner and T. R. F. Wright, Vol. 2c, pp. 1-42. Academic Press, London. 